\title{
Mortality in pulmonary arterial hypertension: prediction by the 2015 European pulmonary hypertension guidelines risk stratification model
}

\author{
Marius M. Hoeper ${ }^{1,2}$, Tilmann Kramer ${ }^{3,4}$, Zixuan Pan $^{5}$, Christina A. Eichstaedt ${ }^{5}$, \\ Jens Spiesshoefer ${ }^{6}$, Nicola Benjamin ${ }^{5}$, Karen M. Olsson ${ }^{1,2}$, Katrin Meyer ${ }^{1}$, \\ Carmine Dario Vizza (10 ${ }^{7}$, Anton Vonk-Noordegraaf ${ }^{8}$, Oliver Distler ${ }^{9}$, \\ Christian Opitz $^{10}$, J. Simon R. Gibbs ${ }^{11}$, Marion Delcroix ${ }^{12}$, H. Ardeschir Ghofrani ${ }^{13}$, \\ Doerte Huscher ${ }^{14}$, David Pittrow ${ }^{15}$, Stephan Rosenkranz ${ }^{3,4}$ and \\ Ekkehard Grünig ${ }^{2,5}$
}

@ERSpublications

The risk stratification strategy proposed by the current European PH guidelines allows accurate survival prediction http://ow.ly/KsWk30c46nK

Cite this article as: Hoeper MM, Kramer T, Pan Z, et al. Mortality in pulmonary arterial hypertension: prediction by the 2015 European pulmonary hypertension guidelines risk stratification model. Eur Respir J 2017; 50: 1700740 [https://doi.org/10.1183/13993003.00740-2017].

ABSTRACT The 2015 European pulmonary hypertension $(\mathrm{PH})$ guidelines propose a risk stratification strategy for patients with pulmonary arterial hypertension (PAH). Low-, intermediate- and high-risk strata are defined by estimated 1 -year mortality risks of $<5 \%, 5-10 \%$ and $>10 \%$, respectively. This risk assessment strategy awaits validation.

We analysed data from patients with newly diagnosed PAH enrolled into COMPERA (Comparative, Prospective Registry of Newly Initiated Therapies for Pulmonary Hypertension), a European-based $\mathrm{PH}$ registry. An abbreviated version of the risk assessment strategy proposed by the European PH guidelines was applied, using the following variables: World Health Organization functional class, 6-min walking distance, brain natriuretic peptide or its $\mathrm{N}$-terminal fragment, right atrial pressure, cardiac index and mixed venous oxygen saturation.

Data from 1588 patients were analysed. Mortality rates were significantly different between the three risk strata $(p<0.001$ for all comparisons). In the entire patient population, the observed mortality rates 1 year after diagnosis were $2.8 \%$ in the low-risk cohort $(n=196), 9.9 \%$ in the intermediate-risk cohort $(n=1116)$ and $21.2 \%$ in the high-risk cohort $(\mathrm{n}=276)$. In addition, the risk assessment strategy proved valid at follow-up and in major PAH subgroups.

An abbreviated version of the risk assessment strategy proposed by the current European $\mathrm{PH}$ guidelines provides accurate mortality estimates in patients with $\mathrm{PAH}$.

This article has supplementary material available from erj.ersjournals.com

Received: April 102017 | Accepted after revision: May 202017

Support statement: This work was supported by the German Centre for Lung Research (DZL) and the Deutsche Forschungsgemeinschaft (M.M. Hoeper, HO 1599/2-1). COMPERA is funded by unrestricted grants from Actelion Pharmaceuticals, Bayer and GSK. These companies were not involved in data analysis or the writing of this manuscript. Funding information for this article has been deposited with the Crossref Funder Registry.

Conflict of interest: Disclosures can be found alongside this article at erj.ersjournals.com 
Affiliations: ${ }^{1}$ Dept of Respiratory Medicine, Hannover Medical School, Hannover, Germany. ${ }^{2}$ German Center of Lung Research (DZL), Germany. ${ }^{3}$ Clinic III for Internal Medicine (Cardiology) and Center for Molecular Medicine (CMMC), Cologne, Germany. ${ }^{4}$ The Cologne Cardiovascular Research Center (CCRC), University of Cologne, Cologne, Germany. ${ }^{5}$ Thoraxclinic at the University Hospital Heidelberg, Heidelberg, Germany. ${ }^{6}$ Dept of Cardiology, University of Dusseldorf, Dusseldorf, Germany. ${ }^{7}$ Dept of Cardiovascular and Respiratory Diseases, Sapienza University of Rome; Rome, Italy. ${ }^{8}$ Dept of Pulmonary Diseases, VU University Medical Center, Amsterdam, The Netherlands. ${ }^{9}$ Dept of Rheumatology, University Hospital, Zurich, Switzerland. ${ }^{10}$ Dept of Cardiology, DRK Kliniken Berlin Westend, Berlin, Germany. ${ }^{11}$ Dept of Cardiology, National Heart and Lung Institute, Imperial College London, London, UK. ${ }^{12}$ Dept of Pneumology, University Hospital Leuven, Leuven, Belgium. ${ }^{13}$ Dept of Pneumology, University of Gießen and Marburg, Germany. ${ }^{14}$ Epidemiology Unit, German Rheumatism Research Centre, (a Leibniz Institute), Berlin, Germany. ${ }^{15}$ Institute for Clinical Pharmacology, Medical Faculty, Technical University, Dresden, Germany.

Correspondence: Marius M. Hoeper, Dept of Respiratory Medicine, Hannover Medical School, 30623 Hannover, Germany. E-mail: hoeper.mariusamh-hannover.de

\section{Introduction}

Pulmonary arterial hypertension (PAH) has evolved from a disease with limited treatment options to one where numerous drugs targeting several pathways have become available. Hence, physicians now can choose between various therapies, modes of administration and drug combinations (recently reviewed in [1-3]). To facilitate treatment decisions, the 2015 European guidelines for pulmonary hypertension (PH) proposed a dynamic risk stratification strategy $[4,5]$. This approach is based on a comprehensive assessment including clinical features, World Health Organization (WHO) functional class (FC), 6-min walking distance (6MWD), cardiopulmonary exercise testing (CPET), biomarkers (brain natriuretic peptide (BNP) and the N-terminal fragment of proBNP (NT-proBNP)) and certain variables derived from echocardiography and right heart catheterisation. Based on cut-off values gathered from the literature, three distinct risk categories have been defined: patients at low risk with an estimated 1 -year mortality rate $<5 \%$; patients at intermediate risk with an estimated 1-year mortality rate of 5-10\%; and patients at high risk with an estimated 1-year mortality rate $>10 \%$. This risk model is meant to be applicable in patients with newly diagnosed PAH and at any time during the course of the disease. However, the accuracy of this risk assessment strategy has not yet been established. The only validation attempt available so far came from the Swedish Pulmonary Arterial Hypertension Registry. These data suggested that the risk stratification strategy proposed by the European $\mathrm{PH}$ guidelines worked accurately at baseline as well as during follow-up, but were based on a relatively small number of patients ( $n=530$ incident patients at baseline and $n=383$ at follow-up) [6].

In order to further validate the risk stratification strategy proposed by the European $\mathrm{PH}$ guidelines, we analysed data from COMPERA (Comparative, Prospective Registry of Newly Initiated Therapies for Pulmonary Hypertension), a European registry that prospectively enrols and follows patients with all forms of $\mathrm{PH}$, including those with $\mathrm{PAH}$.

\section{Methods}

Database

COMPERA (www.COMPERA.org; registered at Clinicaltrials.gov with identifier NCT01347216) is an ongoing web-based PH registry launched in 2007 which collects baseline, follow-up and outcome data from patients who receive targeted therapies for $\mathrm{PH}$. Specialised centres in several European countries participate (Austria, Belgium, Germany, Greece, Hungary, Italy, Netherlands, Switzerland and the United Kingdom), with $\sim 80 \%$ of the patients coming from German $\mathrm{PH}$ centres.

COMPERA enrols only patients with newly diagnosed $\mathrm{PH}$, i.e. patients must be entered into the database no later than 6 months after the date of diagnosis. COMPERA applies a series of state-of-the-art quality checks including automated queries of out-of-range data, individual queries of data that raise concerns and independent on-site source data verification. Further details of COMPERA have been published elsewhere [7-9].

The variables captured in COMPERA are prespecified. Some, but not all variables proposed for risk assessment in the European PH guidelines are regularly recorded in the database. Specifically, WHO FC, $6 \mathrm{MWD}, \mathrm{BNP}$ or NT-proBNP, right atrial pressure, cardiac index and mixed venous oxygen saturation $\left(\mathrm{S}_{\mathrm{VO}_{2}}\right)$ are recorded whenever available. These six variables were used in the present study for the validation of a truncated version of the risk assessment strategy proposed by the European PH guidelines. Variables listed in the guidelines that are not captured in COMPERA are disease progression, syncope, echocardiographic variables and CPET data.

\section{Patients}

Patients were selected from the COMPERA database according to the following criteria: 1) treatment-naïve patients newly diagnosed with PAH between January 1, 2009 and December 1, 2016 with data from 
baseline and at least one follow-up visit available; 2) mean pulmonary artery pressure $\geqslant 25 \mathrm{mmHg}$, pulmonary artery wedge pressure $\leqslant 15 \mathrm{mmHg}$ and pulmonary vascular resistance (PVR) $>240 \mathrm{dyn} \cdot \mathrm{s} \cdot \mathrm{cm}^{-5}$ at the time of diagnosis; and 3) at least two of the six listed variables available at baseline.

\section{Risk stratification strategy}

An abbreviated version of the 2015 European Society of Cardiology (ESC)/European Respiratory Society (ERS) risk stratification strategy was used to categorise patients as low, intermediate or high risk (table 1). Following a validation strategy proposed by Kylhammar et al. [6], the cut-off values proposed in the guidelines were graded 1-3 (1: low risk, 2: intermediate risk and 3: high risk). For each patient, the sum of all grades was divided by the number of available variables and rounded to the next integer to define the risk group. Calculations were made from baseline assessments and from follow-up assessments between 3 months and 2 years after the initiation of medical therapy for PAH.

\section{Statistical analyses}

The primary analysis set consisted of the entire patient population that fulfilled the inclusion criteria listed earlier. Sensitivity analyses were performed with those patients for whom all six risk score variables were available and for the subgroups of patients with idiopathic, drug-associated or hereditary PAH (I/D/ $\mathrm{H}-\mathrm{PAH}$ ) and connective-tissue disease-associated PAH (CTD-PAH). Other subgroups were not assessed because the numbers of patients were considered too low.

Patients who underwent lung transplantation were censored at the time of surgery.

For the follow-up risk stratification, patients who underwent their first comprehensive follow-up risk assessment between 3 months and 2 years after treatment initiation were considered. Where available, we chose the first visit that included follow-up haemodynamics. If no haemodynamic follow-up was available during the first 2 years after diagnosis, we selected the follow-up visit that contained most of the data of interest. For all analyses, only patients with at least one further follow-up were included into the analysis.

Continuous data are presented as mean \pm SD or as median and interquartile range. In patients who died, investigators were asked to provide the most likely cause of death. There was no independent adjudication of causes of death. Survival was evaluated using Kaplan-Meier analysis and log-rank test, truncated at 5 years. Hazard ratios for the single risk-score items were estimated using Cox regression analysis, using the respective low-risk group as reference. IBM SPSS Statistics (version 19.0; Armonk, NY, USA) was used for analysis.

\section{Results}

Risk stratification at baseline and mortality

For this analysis, baseline data from a total of 1588 patients with newly diagnosed PAH fulfilling the inclusion criteria were available. Patients with I/D/H-PAH formed the largest subgroup ( $\mathrm{n}=1060 ; 67 \%)$, followed by patients with CTD-PAH $(n=347 ; 22 \%)$, patients with PAH associated with congenital heart disease $(n=70,4 \%)$ and patients with other forms of PAH $(n=111 ; 7 \%)$. The characteristics of these patients are shown in table 2. Out of the six variables of interest for this study, at least two were available in all 1588 patients (primary analysis set), at least three in 1580 (99.4\%) patients, at least four in 1515 (95.3\%) patients, at least five in $1312(82.6 \%)$ patients and all six variables were available in $879(55.4 \%)$ patients.

$28(1.8 \%)$ patients were lost to follow-up: six (2.8\%) in the low-risk group, $16(1.4 \%)$ in the intermediate-risk group and six (2.3\%) in the high-risk group. 14 (0.9\%) patients underwent lung

\begin{tabular}{|c|c|c|c|}
\hline & Low risk & Intermediate risk & High risk \\
\hline WHO FC & $\mid / I I$ & III & IV \\
\hline 6-min walking distance $\mathrm{m}$ & $>440$ & $165-440$ & $<165$ \\
\hline BNP $n g \cdot L^{-1}$ & $<50$ & $50-300$ & $>300$ \\
\hline NT-proBNP ng. $\mathrm{L}^{-1}$ & $<300$ & $300-1400$ & $>1400$ \\
\hline Right atrial pressure $\mathrm{mmHg}$ & $<8$ & 8-14 & $>14$ \\
\hline Cardiac index $\mathrm{L} \cdot \mathrm{min}^{-1} \cdot \mathrm{m}^{-2}$ & $\geqslant 2.5$ & $2.0-2.4$ & $<2.0$ \\
\hline $\mathrm{SvO}_{2} \%$ & $>65$ & $60-65$ & $<60$ \\
\hline
\end{tabular}

WHO FC: World Health Organization functional class; BNP: brain natriuretic peptide; NT-proBNP: $\mathrm{N}$-terminal fragment of pro-brain natriuretic peptide; $\mathrm{SvO}_{2}$ : mixed venous oxygen saturation. 
TABLE 2 Characteristics of the patients included in the baseline risk stratification group

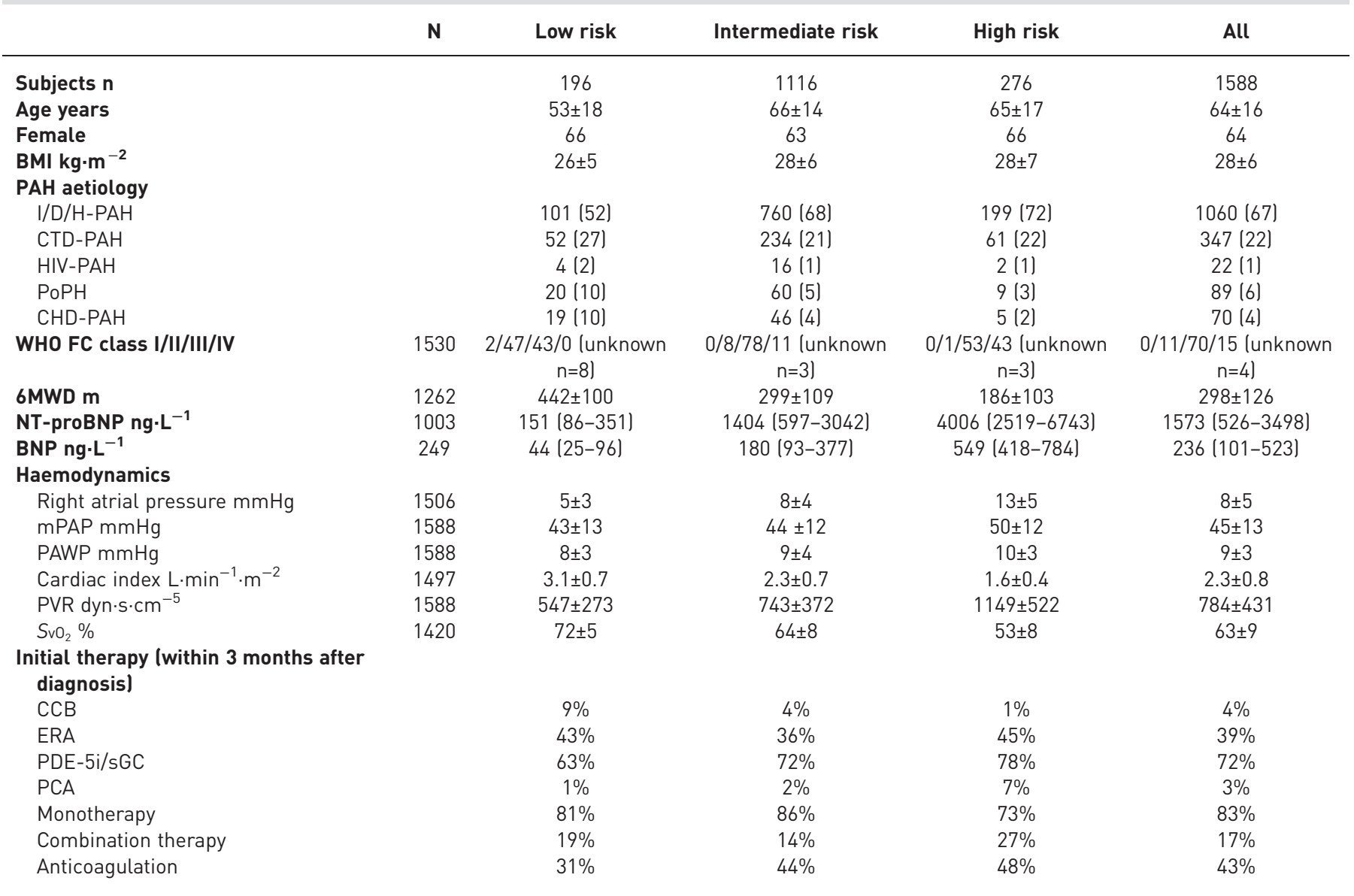

Data are presented as mean $\pm \mathrm{SD}, \mathrm{n}(\%)$ or median (interquartile range), unless otherwise stated. BMI: body mass index; PAH: pulmonary arterial hypertension; I/D/H: idiopathic, drug-associated or hereditary; CTD: connective tissue disease; PoPH: portopulmonary hypertension; CHD: congenital heart disease; WHO FC: World Health Organization functional class; 6MWD: 6-min walking distance; NT-proBNP: N-terminal fragment of pro-brain natriuretic peptide; BNP: brain natriuretic peptide; mPAP: mean pulmonary arterial pressure; PAWP: pulmonary arterial wedge pressure; PVR: pulmonary vascular resistance; $\mathrm{Svo}_{2}$ : mixed venous oxygen saturation; CCB: calcium channel blocker; ERA: endothelin receptor antagonist; PDE-5i: phosphodiesterase-5 inhibitor; sGC: stimulator of soluble guanylate cyclase; PCA: prostacyclin analogue.

transplantation: one $(0.5 \%)$ in the low-risk group, $10(0.9 \%)$ in the intermediate-risk group and three $(1.1 \%)$ in the high-risk group.

Within 5 years after the diagnosis of PAH, 459 (29\%) patients had died: 26 (13.3\%) in the low-risk group, $312(28.0 \%)$ in the intermediate-risk group and 121 (43.8\%) in the high-risk group. Right heart failure was reported as the most likely cause of death in $38 \%$ of the patients who died in the low-risk group, in $54 \%$ of the patients who died in the intermediate-risk group and in $63 \%$ of the patients who died in the high-risk group.

In the low-risk group, the survival rates at 1, 2, 3, 4 and 5 years were $97.2 \%, 91.5 \%, 84.2 \%, 80.2 \%$ and $75.9 \%$, respectively. The corresponding survival rates in the intermediate-risk group were $90.1 \%, 80.3 \%$, $68.1 \%, 60.1 \%$ and $51.9 \%$, respectively and $78.8 \%, 66.0 \%, 53.2 \%, 44.7 \%$ and $32.4 \%$, respectively, in the high-risk group $(\mathrm{p}<0.001$ for all group comparisons; figure 1$)$.

Almost identical results were obtained from a sensitivity analysis that included only those 879 patients for whom all six baseline variables were available. Here, the survival differences between the three risk categories were highly statistically significant, with $\mathrm{p}$-values $<0.001$ for all comparisons (online supplementary table S1 and figure S1).

The predictive value of each variable at baseline is shown in figure 2.

The results of the analyses from the I/D/H-PAH and CTD-PAH subgroups are shown in online supplementary table S2 and figure S2 and online supplementary table S3 and figure S3, respectively. In 
FIGURE 1 Kaplan-Meier survival estimates in patients with all forms of pulmonary arterial hypertension (PAH) combined per individual risk stratification at baseline.

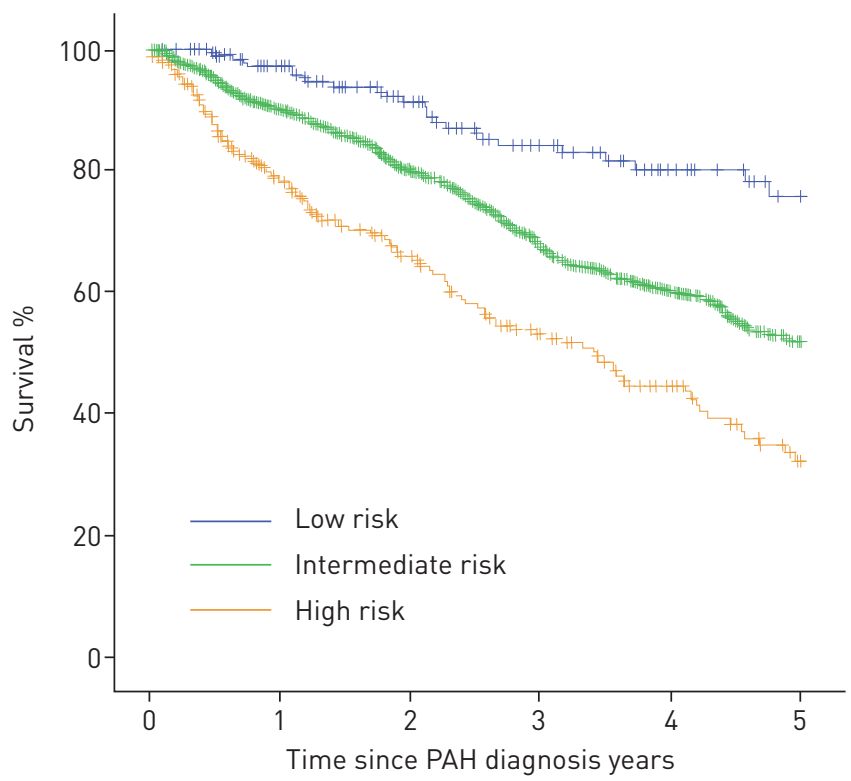

\begin{tabular}{lcccccc}
\hline $\begin{array}{l}\text { Years } \\
\text { after } \\
\text { enrolment }\end{array}$ & \multicolumn{3}{c}{ Survival \% } & \multicolumn{3}{c}{ Cases left n } \\
\cline { 2 - 7 } & $\begin{array}{c}\text { Low } \\
\text { risk }\end{array}$ & $\begin{array}{c}\text { Intermediate } \\
\text { risk }\end{array}$ & $\begin{array}{c}\text { High } \\
\text { risk }\end{array}$ & $\begin{array}{c}\text { Low } \\
\text { risk }\end{array}$ & $\begin{array}{c}\text { Intermediate } \\
\text { risk }\end{array}$ & $\begin{array}{c}\text { High } \\
\text { risk }\end{array}$ \\
\hline 0 & 100 & 100 & 100 & 196 & 1116 & 276 \\
1 & 97.2 & 90.1 & 78.8 & 156 & 764 & 170 \\
2 & 91.5 & 80.3 & 66.0 & 111 & 540 & 117 \\
3 & 84.2 & 68.1 & 53.2 & 75 & 376 & 77 \\
4 & 80.2 & 60.1 & 44.7 & 47 & 252 & 47 \\
5 & 75.9 & 51.9 & 32.4 & 31 & 149 & 24 \\
\hline
\end{tabular}

patients with $\mathrm{I} / \mathrm{D} / \mathrm{H}-\mathrm{PAH}$, the survival differences between all three groups were highly statistically significant $(\mathrm{p}<0.001$; online supplementary figure $\mathrm{S} 2$ ). In patients with CTD-PAH, there was no significant survival difference between the low-risk group and the intermediate-risk group at baseline $(\mathrm{p}=0.101)$, while the survival differences between the high-risk group and the two other groups were highly statistically significant $(\mathrm{p}<0.001$; online supplementary figure $\mathrm{S} 3)$.

Hazard ratio $(95 \% \mathrm{Cl})$

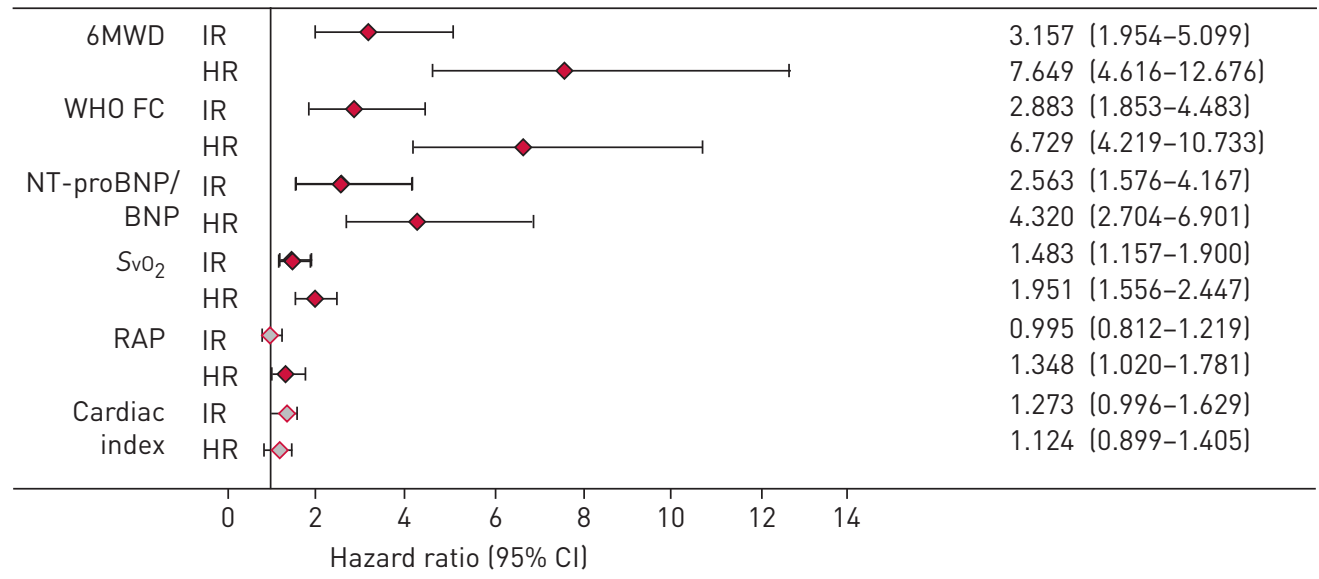

FIGURE 2 Forest plot showing the prognostic values of 6-min walking distance (6MWD), World Health Organization (WHO) functional class (FC), brain natriuretic peptide (BNP) or N-terminal fragment of pro-brain natriuretic peptide (NT-proBNP), mixed venous oxygen saturation ( $\left.\mathrm{SvO}_{2}\right)$, right atrial pressure (RAP) and cardiac index in the intermediate-risk (IR) and high-risk (HR) groups. Values for the parameters were obtained at baseline. The reference value is from the respective low-risk group. 
TABLE 3 Variables obtained between 3 months and 2 years after treatment initiation of patients included in the follow-up risk stratification group

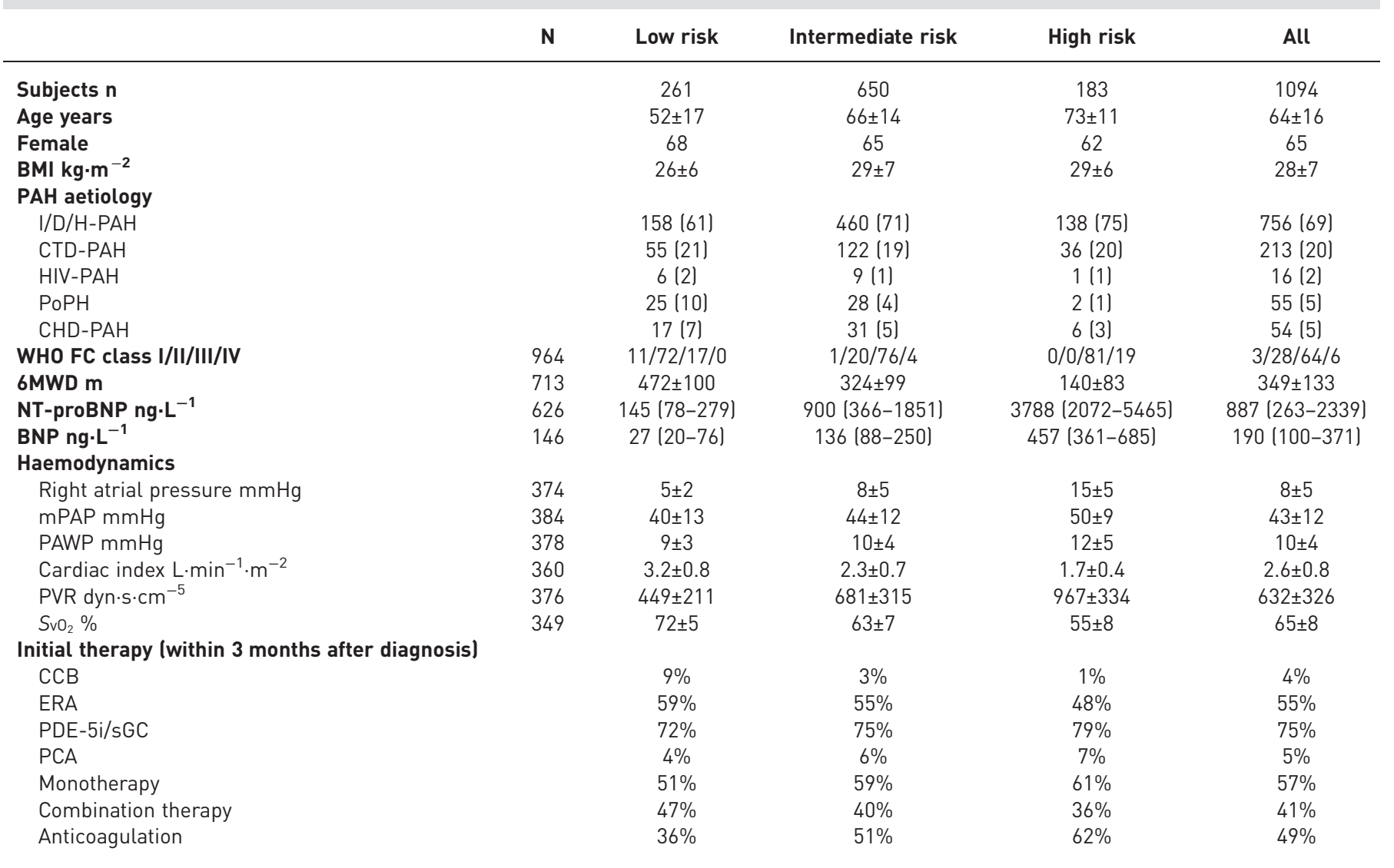

Data are presented as mean \pm SD, $n(\%)$ or median (interquartile range), unless otherwise stated. BMI: body mass index; PAH: pulmonary arterial hypertension; I/D/H: idiopathic, drug-associated or hereditary; CTD: connective tissue disease; PoPH: portopulmonary hypertension; CHD: congenital heart disease; WHO FC: World Health Organization functional class; 6MWD: 6-min walking distance; NT-proBNP: N-terminal fragment of pro-brain natriuretic peptide; BNP: brain natriuretic peptide; mPAP: mean pulmonary arterial pressure; PAWP: pulmonary arterial wedge pressure; PVR: pulmonary vascular resistance; $\mathrm{SvO}_{2}$ : mixed venous oxygen saturation; CCB: calcium channel blocker; ERA: endothelin receptor antagonist; PDE-5i: phosphodiesterase-5 inhibitor; sGCs: stimulator of soluble guanylate cyclase; PCA: prostacyclin analogue.

Risk stratification at follow-up and mortality risk

Follow-up data between 3 months and 2 years after treatment initiation were available for 1355 patients (online supplementary figure S4). Out of the six variables of interest for this study, at least two were available at the same visit in $1230(90.8 \%)$ patients, at least three in $720(53.1 \%)$ patients, at least four in $379(28.0 \%)$ patients, at least five in $270(19.9 \%)$ patients and all six variables were available in $117(8.6 \%)$ patients. Of the patients with at least two risk score variables (assessment in median 7.2 months after baseline), data from at least one additional follow-up visit were available from 1094 patients. The characteristics of these patients are shown in table 3. Haemodynamic follow-up data were available for only $386(35 \%)$ of these patients.

Within 5 years of follow-up assessment, 331 (30.3\%) patients had died: 39 (14.9\%) in the low-risk group, $201(30.9 \%)$ in the intermediate-risk group and 91 (49.7\%) in the high-risk group. In the low-risk group, the survival rates at $1,2,3,4$ and 5 years were $96.5 \%, 91.4 \%, 86.8 \%, 79.8 \%$ and $68.1 \%$, respectively. The corresponding survival rates were $91.8 \%, 78.0 \%, 66.8 \%, 59.3 \%$ and $51.1 \%$, respectively, in the intermediate-risk group, and $72.4 \%, 56.6 \%, 44.2 \%, 28.0 \%$ and $22.8 \%$, respectively, in the high-risk group $(\mathrm{p}<0.001$ for all group comparisons; figure 3$)$.

The results of the follow-up analyses from the I/D/H-PAH and CTD-PAH subgroups are shown in online supplementary tables S2 and S3 and supplementary figures S2 and S3, respectively. In patients with I/D/ $\mathrm{H}-\mathrm{PAH}$, the survival differences between all three groups were statistically significant (low-versus intermediate-risk group $\mathrm{p}=0.002$; low- and intermediate-versus high-risk group both $\mathrm{p}<0.001$; online supplementary figure S5). In patients with CTD-PAH, the survival difference between the low-risk group 
FIGURE 3 Kaplan-Meier survival estimates of patients with all forms of pulmonary arterial hypertension (PAH) combined per individual risk stratification at follow-up risk assessment between 3 months and 2 years.

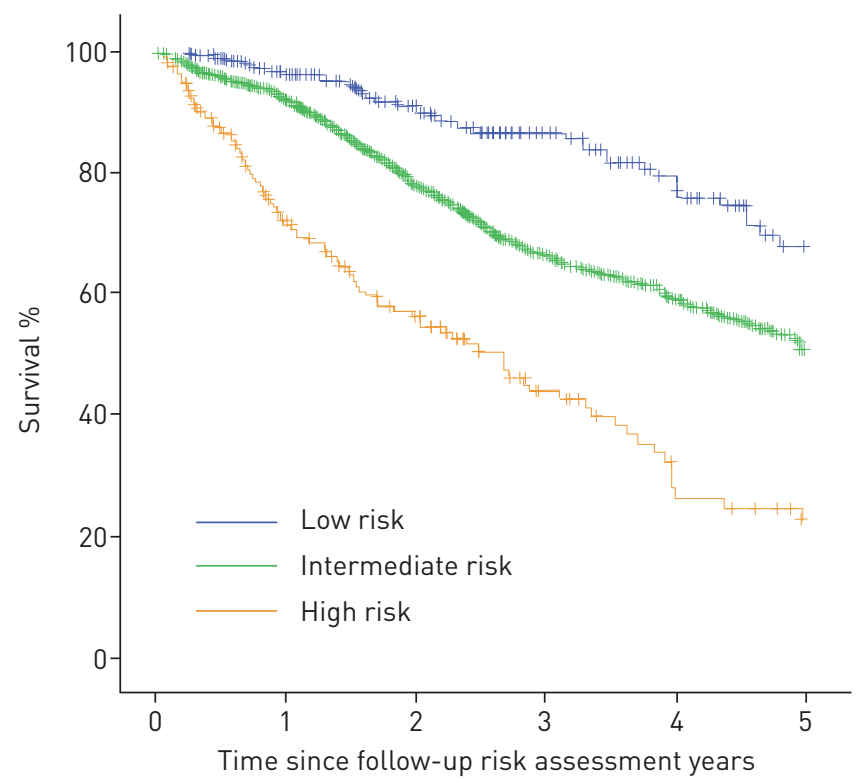

\begin{tabular}{lccccccc}
\hline Years & \multicolumn{3}{c}{ Survival \% } & \multicolumn{3}{c}{ Cases left n } \\
\cline { 2 - 7 } $\begin{array}{l}\text { after } \\
\text { enrolment }\end{array}$ & $\begin{array}{c}\text { Low } \\
\text { risk }\end{array}$ & $\begin{array}{c}\text { Intermediate } \\
\text { risk }\end{array}$ & $\begin{array}{c}\text { High } \\
\text { risk }\end{array}$ & $\begin{array}{c}\text { Low } \\
\text { risk }\end{array}$ & $\begin{array}{c}\text { Intermediate } \\
\text { risk }\end{array}$ & $\begin{array}{c}\text { High } \\
\text { risk }\end{array}$ \\
\hline 0 & 100 & 100 & 100 & 261 & 650 & 183 \\
1 & 96.5 & 91.8 & 72.4 & 203 & 504 & 100 \\
2 & 91.4 & 78.0 & 56.6 & 145 & 355 & 66 \\
3 & 86.8 & 66.8 & 44.2 & 101 & 235 & 35 \\
4 & 79.8 & 59.3 & 28.0 & 67 & 146 & 18 \\
5 & 68.1 & 51.1 & 22.8 & 35 & 79 & 11 \\
\hline
\end{tabular}

and the intermediate-risk group was of marginal statistical significance $(p=0.042)$, while the survival differences between the high-risk group and the two other groups were highly statistically significant $(\mathrm{p}<0.001$; online supplementary figure S6).

The predictive value of each variable at follow-up were not calculated as BNP/NT-proBNP and follow-up haemodynamics were not available from a large proportion of the patients.

From baseline to follow-up, 247 (23.0\%) out of 1073 improved their risk category; 667 (62.2\%) out of 1073 remained stable and 159 (14.8\%) out of 1073 deteriorated. Changes in the risk category from baseline to follow-up were associated with a shift in the mortality risk, as shown in figure 4 .

\section{Discussion}

The main findings of the present study can be summarised as follows. 1) An abbreviated version of the risk stratification strategy proposed by the European $\mathrm{PH}$ guidelines using WHO FC, 6MWD, BNP or NT-proBNP, right atrial pressure, cardiac index and $\mathrm{SvO}_{2}$ discriminated effectively between patients with a low, intermediate and high risk of death; 2) this risk stratification strategy was valid for baseline and follow-up assessments; 3) risk prediction proved accurate for subgroups of patients with I/D/H-PAH and CTD-PAH (except for the lack of a significant survival difference between low- and intermediate-risk CTD-PAH patients at baseline); and 4) the risk estimates proposed in the European $\mathrm{PH}$ guidelines with annual mortality risks of $<5 \%, 5-10 \%$ and $>10 \%$ in patients at low, intermediate or high risk, respectively, were confirmed in the present series, both at baseline as well as at follow-up.

In addition, among the patients who died, the likelihood of death attributed by the investigators to PAH increased from $38 \%$ in the low-risk group to $63 \%$ in the high-risk group. Although assigning causes of death is often associated with uncertainties, these findings suggest that a substantial proportion of patients, especially in the low-risk group, died from causes unrelated to $\mathrm{PAH}$, which may be expected in a relatively old patient population.

Our data confirm and extend previous findings by Kylhammar et al. [6], who used basically the same subset of variables (plus right atrial area and the presence/absence of pericardial effusion). In that study, 


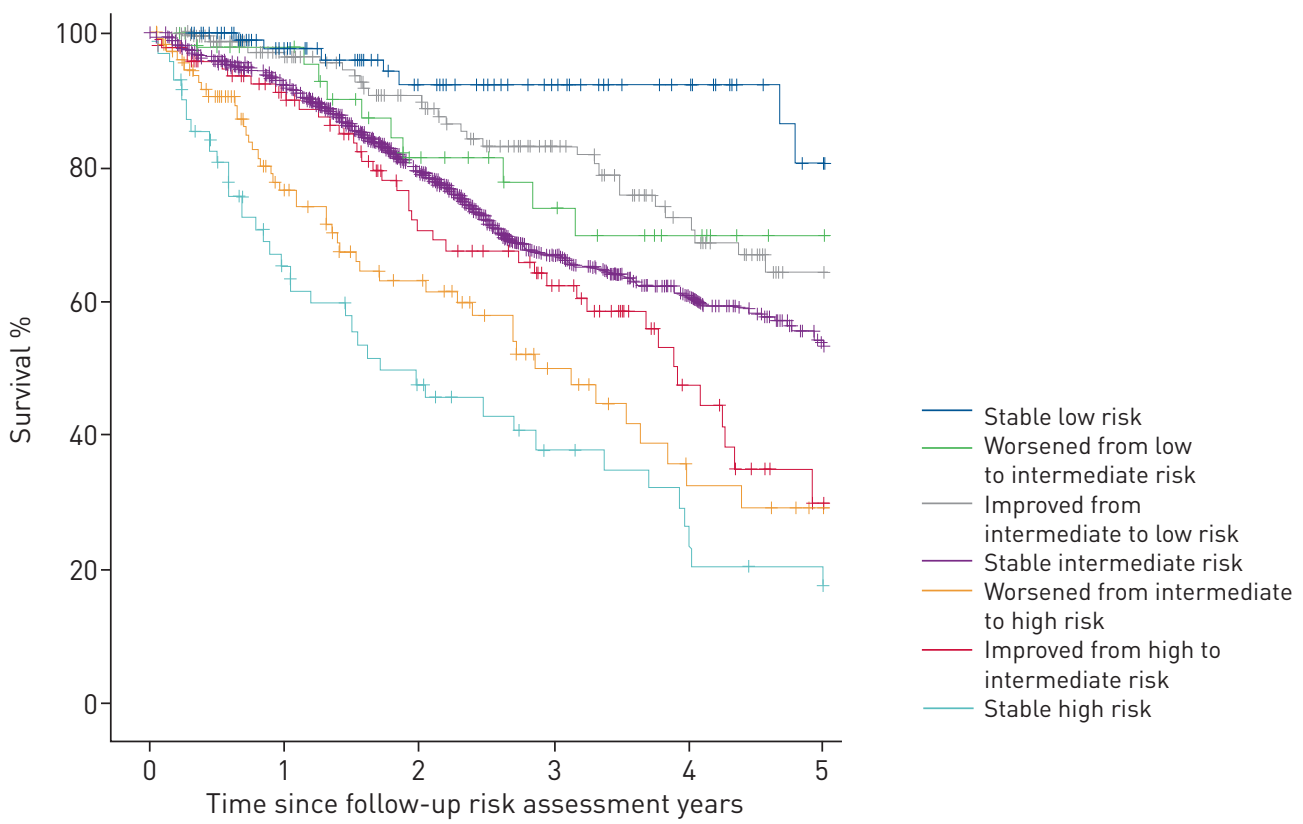

\begin{tabular}{|c|c|c|c|c|c|c|c|}
\hline \multirow[b]{2}{*}{$\begin{array}{l}\text { Years } \\
\text { after } \\
\text { enrolment }\end{array}$} & \multicolumn{7}{|c|}{ Survival \% } \\
\hline & $\begin{array}{l}\text { Stable } \\
\text { low risk }\end{array}$ & $\begin{array}{l}\text { Worsened from } \\
\text { low to } \\
\text { intermediate } \\
\text { risk }\end{array}$ & $\begin{array}{l}\text { Improved from } \\
\text { intermediate to } \\
\text { low risk }\end{array}$ & $\begin{array}{c}\text { Stable } \\
\text { intermediate } \\
\text { risk }\end{array}$ & $\begin{array}{l}\text { Worsened from } \\
\text { intermediate } \\
\text { to high risk }\end{array}$ & $\begin{array}{l}\text { Improved from } \\
\text { high to } \\
\text { intermediate } \\
\text { risk }\end{array}$ & $\begin{array}{c}\text { Stable high } \\
\text { risk }\end{array}$ \\
\hline 0 & 100.0 & 100.0 & 100.0 & 100.0 & 100.0 & 100.0 & 100.0 \\
\hline 1 & 97.4 & 97.8 & 96.3 & 91.6 & 76.5 & 89.9 & 65.3 \\
\hline 2 & 92.2 & 81.4 & 90.7 & 79.1 & 63.1 & 70.4 & 47.7 \\
\hline 3 & 92.2 & 73.8 & 83.1 & 67.0 & 49.9 & 62.3 & 38.2 \\
\hline 4 & 92.2 & 69.7 & 72.4 & 60.5 & 32.6 & 47.5 & 23.5 \\
\hline \multirow[t]{2}{*}{5} & 80.6 & 69.7 & 64.4 & 53.3 & 29.3 & 30.0 & 17.1 \\
\hline & \multicolumn{7}{|c|}{ Patients at risk $\mathrm{n}$} \\
\hline $\begin{array}{l}\text { Years } \\
\text { after } \\
\text { enrolment }\end{array}$ & $\begin{array}{l}\text { Stable } \\
\text { low risk }\end{array}$ & $\begin{array}{c}\text { Worsened from } \\
\text { low to } \\
\text { intermediate } \\
\text { risk }\end{array}$ & $\begin{array}{l}\text { Improved from } \\
\text { intermediate to } \\
\text { low risk }\end{array}$ & $\begin{array}{c}\text { Stable } \\
\text { intermediate } \\
\text { risk }\end{array}$ & $\begin{array}{l}\text { Worsened from } \\
\text { intermediate } \\
\text { to high risk }\end{array}$ & $\begin{array}{l}\text { Improved from } \\
\text { high to } \\
\text { intermediate } \\
\text { risk }\end{array}$ & $\begin{array}{c}\text { Stable high } \\
\text { risk }\end{array}$ \\
\hline 0 & 93 & 49 & 152 & 504 & 110 & 95 & 70 \\
\hline 1 & 71 & 39 & 118 & 391 & 63 & 74 & 35 \\
\hline 2 & 46 & 26 & 88 & 282 & 42 & 47 & 23 \\
\hline 3 & 31 & 19 & 62 & 181 & 21 & 34 & 14 \\
\hline 4 & 22 & 12 & 40 & 117 & 10 & 16 & 8 \\
\hline 5 & 13 & 7 & 21 & 68 & 6 & 4 & 5 \\
\hline
\end{tabular}

FIGURE 4 Landmark analysis showing survival according to change in risk category from baseline to follow-up within 3 months and 2 years in patients with pulmonary arterial hypertension. This figure is based on $n=1073$ patients; those who changed from low to high risk or vice versa ( $n=23$ in total) were excluded due to low numbers.

which included 530 Swedish patients with newly diagnosed PAH, the three risk groups had significantly different long-term survival rates, similar to our study. The present study was almost three times the size of the Swedish dataset. Together, these two studies comprise 2000 patients with PAH and provide independent validation of the ESC/ERS risk stratification strategy.

Some additional findings of the present study are worthy of discussion: in our series, $12 \%$ of the patients presented in the low-risk category at the time of diagnosis. This proportion increased to $24 \%$ at follow-up. In the Swedish PH registry, the proportion of low-risk patients was $23 \%$ at baseline and $29 \%$ at follow-up. The reasons for these differences are unclear and may partly reflect the slightly different variables used for risk assessment in the two studies. Of note, the proportion of patients with a low-risk profile was small in the two cohorts, both at baseline and at follow-up. According to the current $\mathrm{PH}$ guidelines, the main objective of PAH therapy is achieving and maintaining a low-risk profile $[4,5]$. This treatment goal was 
not achieved in the majority of our patients. At the same time, our data indicate that combinations of $\mathrm{PAH}$ drugs were used in only $19 \%$ of all patients at baseline (i.e. within the first 3 months after diagnosis) and in $41 \%$ at follow-up. Even in the high-risk cohort, combination therapy was used in only $17 \%$ of the patients at baseline and in $36 \%$ at follow-up. Intravenous or subcutaneous prostacyclin analogues were virtually absent in this study ( $7 \%$ in high-risk patients at follow-up). Given that there is now ample

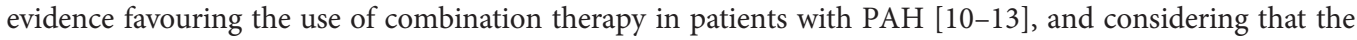
present ESC/ERS guidelines recommend initial combination therapy including intravenous prostacyclin for patients presenting at high risk $[4,5]$, it is surprising to see that monotherapy was still used in the majority of patients. One potential reason for this reluctance may be the fact that the patients in the present series were relatively old; it is possible that the presence of comorbidities may have led physicians to prefer monotherapies [7, 9]. In addition, the enrolment period for the present analysis started in 2009, when there was less evidence supporting the use of combination therapy in patients with PAH. It will be interesting to see whether the use of combination therapy increases in the future and whether this will be accompanied by better outcomes.

The 2015 ESC/ERS guidelines recommend a comprehensive risk assessment strategy based on 13 variables $[4,5]$. Another widely used risk stratification tool is the REVEAL risk score, which consists of 19 variables, but has been shown to remain valid when fewer variables are used [14, 15]. The present study demonstrated that an abbreviated version of the ESC/ERS risk assessment strategy using only six or fewer selected variables provided accurate distinction between the risk groups. Variables closely linked to the mortality risk were $6 \mathrm{MWD}$, WHO FC, BNP/NT-proBNP and $\mathrm{SvO}_{2}$, whereas right atrial pressure and cardiac index performed less well. These findings are only partly in line with a previous study by NiCKEL et al. [16], which showed that among various variables used for risk stratification, only WHO FC, NT-proBNP, cardiac index and $\mathrm{S}_{\mathrm{vO}_{2}}$ provided independent prognostic information. Hence, it seems possible to use a selected number of variables for accurate discrimination of risk groups. However, given the fact that several variables from echocardiography and cardiopulmonary exercise testing were not available for our present analysis, further studies are needed to determine the most reliable dataset.

Changes in the risk category, regardless of the direction, seem to be an accurate predictor of long-term survival and may therefore be considered end-points in future clinical trials. In the present series, $48 \%$ of the patients with newly diagnosed $\mathrm{PAH}$ had experienced a change in the risk category from baseline to follow-up, determined mainly by changes in functional class, 6MWD and BNP/NT-proBNP. Hence, a combination of simple and noninvasive tools provides important prognostic information. Previous long-term studies have focused on clinical worsening $[10,11,17,18]$, but our data suggest that statistical tools determining the net benefit, i.e. the ratio of patients who improve or worsen their risk category, could increase the power of clinical trials.

Our study had several strengths and limitations. Perhaps the greatest strength was the large number of prospectively documented, newly diagnosed patients with PAH. Hence, the sample size was large enough to provide sufficient patient numbers in all three risk strata and to allow subgroup analyses, at least for patients with I/D/H-PAH and for patients with CTD-PAH. However, further research is necessary to determine whether our risk calculation approach was appropriate or whether alternative models might provide even better prognostication. One of the most important limitations of our study was the fact that not all variables included in the risk stratification strategy proposed by the European $\mathrm{PH}$ guidelines were available. Information on disease progression, syncope, CPET and echocardiography were missing. In addition, and perhaps most importantly, follow-up haemodynamics were available only from 386 patients within 3 months and 2 years after inclusion, i.e. $\sim 35 \%$ of the patients who had follow-up data, which limits the ability of the present study to fully analyse the predictive value of invasive and noninvasive variables at follow-up. Further studies should determine whether a strategy based on a few selected parameters provides sufficient prognostic information and how much information follow-up haemodynamics add to noninvasive tools.

It may be seen as another limitation that patients enrolled in COMPERA tend to be relatively old, at least compared to other PAH registries. However, the data reflect the real-world scenario in the participating centres, particularly in Germany, and a PAH registry from Sweden has recently reported almost identical demographics [19].

In conclusion, our data show that an abbreviated version of the risk stratification strategy proposed by the current ESC/ERS PH guidelines provides an accurate prediction of mortality. The observed 1-year mortality rates are $<5 \%$ in low-risk patients, between $5 \%$ and $10 \%$ in intermediate-risk patients and $>10 \%$ in high-risk patients. Predictions were accurate for baseline as well as follow-up assessments. Further research is needed to determine which sets of variables have the best predictive performance and to assess the usefulness of risk categorisation strategies in clinical trials. In addition, our data show that a low-risk 
profile is achieved only in a minority of patients with PAH. Improving this figure should be a major objective of future research.

\section{Acknowledgements}

The authors are indebted to the COMPERA investigators.

\section{References}

1 Hoeper MM, McLaughlin VV, Dalaan AM, et al. Treatment of pulmonary hypertension. Lancet Respir Med 2016; 4: 323-336.

2 Humbert M, Lau EM, Montani D, et al. Advances in therapeutic interventions for patients with pulmonary arterial hypertension. Circulation 2014; 130: 2189-2208.

3 McLaughlin VV, Shah SJ, Souza R, et al. Management of pulmonary arterial hypertension. J Am Coll Cardio 2015; 65: 1976-1997.

4 Galiè N, Humbert M, Vachiery JL, et al. 2015 ESC/ERS Guidelines for the diagnosis and treatment of pulmonary hypertension: The Joint Task Force for the Diagnosis and Treatment of Pulmonary Hypertension of the European Society of Cardiology (ESC) and the European Respiratory Society (ERS). Eur Heart J 2016; 37: 67-119.

5 Galie N, Humbert M, Vachiery JL, et al. 2015 ESC/ERS Guidelines for the diagnosis and treatment of pulmonary hypertension: The Joint Task Force for the Diagnosis and Treatment of Pulmonary Hypertension of the European Society of Cardiology (ESC) and the European Respiratory Society (ERS). Eur Respir J 2015; 46: 903-975.

6 Kylhammar D, Kjellström B, Hjalmarsson C, et al. A comprehensive risk stratification at early follow-up determines prognosis in pulmonary arterial hypertension. Eur Heart J 2017; In press doi:10.1093/eurheartj/ehx257.

7 Hoeper MM, Huscher D, Ghofrani HA, et al. Elderly patients diagnosed with idiopathic pulmonary arterial hypertension: results from the COMPERA registry. Int J Cardiol 2013; 168: 871-880.

8 Hoeper MM, Behr J, Held M, et al. Pulmonary hypertension in patients with chronic fibrosing idiopathic interstitial pneumonias. PLoS One 2015; 10: e0141911.

9 Opitz CF, Hoeper MM, Gibbs JS, et al. Pre-capillary, combined, and post-capillary pulmonary hypertension: a pathophysiological continuum. J Am Coll Cardiol 2016; 68: 368-378.

10 Pulido T, Adzerikho I, Channick RN, et al. Macitentan and morbidity and mortality in pulmonary arterial hypertension. N Engl J Med 2013; 369: 809-818.

11 Galiè N, Barberà JA, Frost AE, et al. Initial use of ambrisentan plus tadalafil in pulmonary arterial hypertension. N Engl J Med 2015; 373: 834-844.

12 Sitbon O, Jaïs $\mathrm{X}$, Savale $\mathrm{L}$, et al. Upfront triple combination therapy in pulmonary arterial hypertension: a pilot study. Eur Respir J 2014; 43: 1691-1697.

13 Lajoie AC, Lauzière G, Lega JC, et al. Combination therapy versus monotherapy for pulmonary arterial hypertension: a meta-analysis. Lancet Respir Med 2016; 4: 291-305.

14 Benza RL, Gomberg-Maitland M, Miller DP, et al. The REVEAL Registry risk score calculator in patients newly diagnosed with pulmonary arterial hypertension. Chest 2012; 141: 354-362.

15 Benza RL, Miller DP, Foreman AJ, et al. Prognostic implications of serial risk score assessments in patients with pulmonary arterial hypertension: a Registry to Evaluate Early and Long-Term Pulmonary Arterial Hypertension Disease Management (REVEAL) analysis. J Heart Lung Transplant 2015; 34: 356-361.

16 Nickel N, Golpon H, Greer M, et al. The prognostic impact of follow-up assessments in patients with idiopathic pulmonary arterial hypertension. Eur Respir J 2012; 39: 589-596.

17 McLaughlin V, Channick RN, Ghofrani HA, et al. Bosentan added to sildenafil therapy in patients with pulmonary arterial hypertension. Eur Respir J 2015; 46: 405-413.

18 Sitbon O, Channick R, Chin KM, et al. Selexipag for the treatment of pulmonary arterial hypertension. $N$ Engl J Med 2015; 373: 2522-2533.

19 Rådegran G, Kjellström B, Ekmehag B, et al. Characteristics and survival of adult Swedish PAH and CTEPH patients 2000-2014. Scand Cardiovasc J 2016; 50: 243-250. 